\title{
A stratified approach to pre-clinical tribological evaluation of joint replacements representing a wider range of clinical conditions advancing beyond the current standard
}

\author{
John Fisher $\dagger^{*}$ \\ Received 4th January 2012, Accepted 10th January 2012 \\ DOI: 10.1039/c2fd00001f
}

\begin{abstract}
A new stratified approach to pre-clinical tribological simulation of joint replacements is presented, which extends beyond present standard conditions used. It includes variations in surgical delivery, variations in kinematics, variations in the patient population and degradation of the biomaterials technology. Examples of the new methods are presented, which have been validated against clinical experience of existing devices. The stratified approach has differentiated the performance of joint replacements, which had previously been shown to have similar tribological performance under standard conditions. The stratified approach to pre-clinical tribological simulation of joint replacements has the potential to support the development of robust designs and improve safety and reliability of joint replacements in the future.
\end{abstract}

\section{Introduction}

Joint replacement is one of the most successful surgical interventions, with over 50 years clinical use. Joint replacements have to transmit biomechanical forces and enable movements for the whole of the patient's lifetime. They are increasingly used in younger more active patients with higher demand, with " 50 active years after 50 ®" and with higher levels of expectations of function, reliability and survivorship. Pre-clinical tribological simulation and evaluation systems allow the performance of the implant system to be evaluated under simulated in vivo biomechanical and kinematic conditions, allowing the contact mechanics, friction, wear, wear debris and biological reactivity to be assessed..$^{1-3}$ Increasing demands and expectations of patients and surgeons now require improved pre-clinical simulation systems and evaluations.

During the period 1960 to 1990 , there was limited pre-clinical tribological evaluation of whole joint prostheses. Recognition of the importance of wear and wear debris induced osteolysis as a major failure mode of hip prostheses during the $1990 \mathrm{~s}^{1-3}$ led to extensive development of hip simulation systems and knee simulation systems. Typically they have applied a simulation of the standard walking cycle, for pre-clinical evaluation of hip prostheses ${ }^{4-6}$ and knee prostheses. ${ }^{7-9}$ Wear rates, wear mechanisms and wear debris from simulators were compared to clinical retrievals for conventional polyethylene to validate the simulation systems. ${ }^{10}$ The average wear

Institute of Medical \& Biological Engineering, School of Mechanical Engineering, University of Leeds, Leeds, LS2 9JT, UK. E-mail:J.Fisher@leeds.ac.uk

$\uparrow$ Statement of potential conflicts of interest: JF is a paid consultant to DePuy, JF and the University of Leeds receive royalty income from DePuy, JF is a share holder and paid adviser to Tissue Regenix. 
rates and debris size and morphologies were found to be similar in the simulator to those found from retrievals for conventional polyethylene. However, there was greater variation in the wear rates and mechanisms found in vivo. Some of this variation was attributed to degradation of the prosthetic biomaterials in vivo due to damage to the metallic femoral head and/or oxidative degradation of the polyethylene material. ${ }^{1-3,10,11}$

The simulation methods using the standard walking cycle, which involve using correctly positioned, concentric and aligned components, have been widely adopted by companies and international standards bodies. These standard simulations have been primarily adopted over the last decade and were validated against clinical studies and retrievals based on the average wear rates. ${ }^{4-6,10}$ They do not replicate or represent the variation in performance found in the patient under a much wider set of clinical conditions.

The standard walking cycle conditions have been applied to demonstrate a reduction in average wear under standard walking cycle conditions with new biomaterials and designs such as cross linked polyethylene, which have subsequently been verified upon introduction of the technology clinically. ${ }^{12}$

Simulation methods using a standard walking cycle and ISO and ASTM recommended standard conditions have also been applied extensively to other alternative bearing materials such as metal on metal and ceramic on ceramic for the hip. Under the standard walking cycle conditions, the wear rate of these bearings is extremely low. ${ }^{13,14}$ While these pre-clinical simulations under standard conditions replicate some of the lower wear rates and wear mechanisms found in vivo for these alternative bearings, they fail to simulate the variation found clinically and in particular fail to replicate some of the higher wear rates and more severe wear mechanism found in some patients and some retrieved components. ${ }^{15}$

The majority of current joint replacement prostheses perform well with low wear under standard walking conditions and indeed are predicted to meet the needs of many patients. However, while an acceptable clinical performance is assessed by NICE as greater than $90 \%$ survivorship at ten years in the average population, there is significant interest in reducing failure rates further, producing more reliable and robust solutions that have low wear under increased demand and accommodate the wide variation in clinical conditions.

It is therefore critically important to be able to pre-clinically evaluate performance under a wider set of clinically relevant conditions, in order to assess the variation and increases in wear rates associated with the different conditions found clinically. In particular it is essential to identify pre-clinically designs that not only have acceptably low wear rates under the standard conditions, but also have low wear rates under a wider set of clinical conditions, a more robust design, and which avoid high wear rates under adverse clinical conditions that can cause failure.

In this paper we present a new systematic and stratified approach to pre-clinical simulation and evaluation of joint prostheses under a wide set of clinical conditions, which advance well beyond the current standard and practice. By analysis of our bank of over 5 billion cycles of pre-clinical data, we have established a baseline reference of acceptable wear performance under standard conditions for different material combinations and provide examples of how our new stratified approach can be used to assess the increase in wear of the different types of prostheses under the wider set of clinical conditions. This allows the magnitude of the risk associated with an increased wear rate to be determined, which can be combined with the frequency of occurrence of the condition to determine the total risk of increased wear.

\section{Methods and the stratified approach}

The current standards for pre-clinical tribological evaluation of joint prostheses define: 
- A correctly positioned prosthesis, with correct rotational and translational positions

- A single standard walking cycle

- An average standard patient, in terms of anatomy and physiology

- A perfect prostheses without degradation

These standard conditions have been used to determine average wear rates for different prosthetic devices from our existing data set, which have been compared to average clinical wear rates. ${ }^{4-14}$

We have defined a new stratified approach to systematically address the wider set of conditions found clinically and have developed and validated examples for the set of new simulation methods for pre-clinical evaluation. The stratified approach includes:

- Conditions associated with variation in the surgical delivery of the device such as rotational and translational mal-position..$^{15-27}$ In particular these relate to the rotational position of the cup and the intersection of the tribological contact patch on the head with the edge of the cup and in the translational positions of the centres of the head and cup, the alignment of their centres to each other and to the natural centre of the hip. Mal-positioning can occur during surgery, but also as a result of impingement, offset deficiency and stem subsidence.

- Conditions associated with different types of patient activities, joint kinematics in the hip, ${ }^{5,27}$ levels of activities, levels of loading, jogging, stop-start motion, levels of swing phase load, ${ }^{28,29}$ different input kinematics ${ }^{30,31}$ and influence of lift off in the knee. $^{32}$

- Conditions associated with different types of patients and stratifications of the population, such as variations in the natural lubricant, ${ }^{33}$ inflammatory response, ${ }^{34}$ metal ion sensitivity, variation in anatomy and physiology and disease state.

- Conditions associated with degradation of the device technology, such as femoral head damage ${ }^{6}$ and oxidative degradation of polyethylene..$^{35,36}$

As the overall tribological performance of the hip prosthesis is dependent on the full set of conditions found clinically, interactions within each and across each set of conditions also need to be considered, but extend beyond scope of current studies. Applying the standard walking conditions simulation and through comparison with average clinical wear rates a normal range for acceptable average wear rates for different materials has been established, which can be associated with clinical success. Using the new stratified approach to pre-clinical testing and selecting particular sets of conditions, examples of the effect of variation in specific conditions on wear rate and mechanism have been determined. The pre-clinical predicted wear results are presented in the context of the normal range of wear rates under standard conditions.

In consideration of the biological response to the wear and wear debris which cause failure, it is also necessary to consider the relative reactivity of different types of wear debris in terms of its type of reaction, inflammation and osteolysis or toxicity and necrosis, as well as severity of response to volumetric doses., ${ }^{2,3}$ Laboratory studies have shown metal debris to have a higher level of toxicity at lower doses than ceramic or polyethylene debris, while ceramic debris has been shown to produce similar or lower levels of inflammatory cytokines to polyethylene debris. This is considered when interpreting relative wear rates under different conditions.

\section{Results}

\section{Results for standard condition wear simulation}

The normal range for average wear rates under standard conditions from pre-clinical simulation studies derived from a single laboratory is given in Table 1. Standard condition simulation studies showed the highest level of wear rate with conventional polyethylene, reducing with cross linked polyethylene, then metal on metal, to the 
Table 1 Results of average wear rates for standard condition simulation studies

\begin{tabular}{|c|c|c|c|c|c|}
\hline $\begin{array}{l}\text { Type } \\
\text { of } \\
\text { bearing }\end{array}$ & $\begin{array}{l}\text { Material } \\
\text { combination }\end{array}$ & $\begin{array}{l}\text { Head size } \\
\text { (range in } \mathrm{mm} \text { ) }\end{array}$ & $\begin{array}{l}\text { Wear rate } \\
\left(\mathrm{mm}^{3} \text { per }\right. \\
\text { million cycles })\end{array}$ & $\begin{array}{l}\text { Source } \\
\text { references }\end{array}$ & Comments \\
\hline Hip & $\begin{array}{l}\text { Metal on conventional } \\
\text { polyethylene }\end{array}$ & 28 & 25 to 40 & $4-6$ & $\begin{array}{l}\text { Validated clinical } \\
\text { study }^{10,11}\end{array}$ \\
\hline Hip & $\begin{array}{l}\text { Metal on cross linked } \\
\text { polyethylene } \\
(7.5-10 \mathrm{MRad})\end{array}$ & $28-36$ & 5 to 10 & 12 & \\
\hline Hip & Metal on metal & 28 & 0.1 to 1 & 14,21 & $\begin{array}{l}\text { Clinical studies } \\
\text { higher }\end{array}$ \\
\hline Hip & Metal on metal & 36 & 0.4 to 0.8 & 36 & $\begin{array}{l}\text { Clinical studies } \\
\text { higher }\end{array}$ \\
\hline Hip & Metal on metal & $39-55$ & 0.1 to 0.4 & 37 & $\begin{array}{l}\text { Clinical studies } \\
\text { higher }\end{array}$ \\
\hline Hip & Ceramic on metal & 28 to 36 & 0.02 to 0.1 & 36 & \\
\hline Hip & $\begin{array}{l}\text { Alumina ceramic } \\
\text { on ceramic }\end{array}$ & 28 & 0.02 to 0.1 & 13 & $\begin{array}{l}\text { Clinical studies } \\
\text { stripe head } \\
\text { wear }^{15}\end{array}$ \\
\hline Hip & $\begin{array}{l}\text { Delta ceramic on } \\
\text { ceramic }\end{array}$ & 28 & 0.02 to 0.1 & 18,25 & $\begin{array}{l}\text { Clinical studies } \\
\text { stripe } \\
\text { head wear }\end{array}$ \\
\hline Knee & $\begin{array}{l}\text { Conventional } \\
\text { polyethylene }\end{array}$ & Medium & 6 to 12 & $8,9,30$ & $\begin{array}{l}\text { Standard } \\
\text { kinematics }\end{array}$ \\
\hline Knee & $\begin{array}{l}\text { Cross linked } \\
\text { polyethylene } \\
(5 \mathrm{MRad})\end{array}$ & Medium & 3 to 6 & & $\begin{array}{l}\text { Standard } \\
\text { kinematics }\end{array}$ \\
\hline
\end{tabular}

lowest with ceramic on metal and ceramic on ceramic. Clinical studies have validated the reduction in average wear with cross linked compared to conventional polyethylene. For conventional polyethylene a wear rate of $40 \mathrm{~mm}^{3}$ per million cycles has been shown to exceed the critical volume of $500 \mathrm{~mm}^{3}$ needed to cause osteolysis at ten years in an active patient. The reduction in wear rate with cross linked polyethylene indicates this risk is substantially reduced. A wear rate of less than $10 \mathrm{~mm}^{3}$ per million cycles was indicative of acceptable wear performance for cross linked polyethylene under standard conditions in a low or medium demand patient.

In metal on metal the different devices showed similar wear rates under standard walking cycle conditions of 0.1 to $1 \mathrm{~mm}^{3}$ per million cycles. There is clinical evidence that this low level of debris may be tolerated from the bearing surfaces, and clinical and retrieval studies show a much greater variation and substantially higher wear rates in individual patients. ${ }^{26}$ Wear rates above $1 \mathrm{~mm}^{3}$ per million cycles were consistent with metal ion levels above $10 \mathrm{ppm}$, which may produce adverse reactions clinically. ${ }^{26}$

In ceramic on ceramic bearings the lowest wear rate was found under standard conditions, less than $0.1 \mathrm{~mm}^{3}$ per million cycles and accurate measurement of wear below this level is difficult in vitro. However the standard wear simulation did not replicate the stripe wear and higher wear rate found on retrieved prostheses. ${ }^{15-17}$ As with metal on metal the standard simulation did not predict the variation or higher levels of wear found clinically. However, the clinical wear rates of the order of $1 \mathrm{~mm}^{3}$ per million cycles for ceramic do not appear to produce adverse reactions.

In the knee with polyethylene bearings the wear rate was reduced with cross linked polyethylene under standard condition testing, showing similar effects to that found in the hip. The wear rate for conventional polyethylene in the knee was less than in 
the hip, which reflects the lower incidence of osteolysis in the knee under normal conditions. Again, as with the hip, a wear rate of less than $10 \mathrm{~mm}^{3}$ per million cycles may be considered an acceptable performance for polyethylene in the knee.

\section{Results for examples of stratified approach for different simulation conditions}

Conditions associated with variation in the surgical delivery of the device. In this section examples of wear under conditions associated with variation in the position of the hip prosthesis are presented, in particular variation in the rotational position of the cup with an increased inclination angle of $60^{\circ}$, variation in the translational position of the head and cup with a microseparation of the centres by $0.5 \mathrm{~mm}$ and a combination of both conditions.

Table 2 shows the results for adverse variation in position. The response to surgical mal-position was dependent on bearing type and design. The Delta ceramic wear rate remained less than $1 \mathrm{~mm}^{3}$ per million cycles, as did the ceramic on metal bearing, which could be considered an acceptable level of wear. In contrast the metal on metal bearings all give wear rates above $1 \mathrm{~mm}^{3}$ per million cycles. The increase was less with the smaller diameter metal on metal total joint replacements, and was greatest with the larger diameter sub hemispherical surface replacement under translational and rotational mal-position. The pre-clinical evaluations which considered the variation in component position were able to differentiate the wear performance of different materials and designs, and provide a potential explanation for variation in clinical performance and outcomes with different designs of metal on metal bearings. Further evidence of the value of this type of pre-clinical testing has been demonstrated in the development of surface engineered bearings for hips, where simulation of mal-positioning and rim loading was able to demonstrate failure of surface coating prior to the device entering clinical trials. ${ }^{38}$

Conditions associated with variations in kinematics. In this section variations in wear rate associated with changes in kinematics inputs in the knee are presented. In particular the effect of higher kinematic inputs, increased anterior posterior translation and also introduction of abduction/adduction lift off and medial lateral translation were studied (Table 3). The wear under high kinematic input conditions for conventional polyethylene increased above $10 \mathrm{~mm}^{3}$ per million cycles with both increased anterior posterior (AP) translation and with the introduction of lift off, abduction/adduction rotation and medial lateral translation. These higher kinematic

Table 2 Wear rates corresponding to adverse variation in position of prostheses

\begin{tabular}{|c|c|c|c|c|c|}
\hline $\begin{array}{l}\text { Prosthesis } \\
\text { type }\end{array}$ & Material & $\begin{array}{l}\text { Size } \\
(\mathrm{mm})\end{array}$ & $\begin{array}{l}\text { Adverse } \\
\text { condition }\end{array}$ & $\begin{array}{l}\text { Wear rate } \\
\left(\mathrm{mm}^{3} \text { per }\right. \\
\text { million cycles })\end{array}$ & $\begin{array}{l}\text { Source } \\
\text { reference }\end{array}$ \\
\hline Hip & Alumina ceramic & 28 & $\begin{array}{l}\text { Translational } \\
\text { mal-position }\end{array}$ & 0.5 to 1.8 & 15,18 \\
\hline Hip & Delta ceramic & 28 & $\begin{array}{l}\text { Translational } \\
\text { mal-position }\end{array}$ & 0.5 to 0.25 & 25 \\
\hline Hip & Metal on metal & 39 & $\begin{array}{l}\text { Rotational } \\
\text { mal-position }\end{array}$ & 1 to 10 & 24 \\
\hline Hip & Metal on metal & 39 & $\begin{array}{l}\text { Translational } \\
\text { rotational } \\
\text { mal-position }\end{array}$ & 8 to 14 & 24 \\
\hline Hip & Metal on metal & 28 & $\begin{array}{l}\text { Translational } \\
\text { mal-position }\end{array}$ & 0.5 to 3 & 36 \\
\hline Hip & Ceramic on metal & 28 & $\begin{array}{l}\text { Translational } \\
\text { mal-position }\end{array}$ & 0.1 to 0.5 & 36 \\
\hline
\end{tabular}


Table 3 Variation in kinematic conditions in the knee

\begin{tabular}{|c|c|c|c|c|c|}
\hline Type & Size & Material & Condition & $\begin{array}{l}\text { Wear rate } \mathrm{mm}^{3} / \\
\text { million cycles }\end{array}$ & Reference \\
\hline Knee & $\begin{array}{l}\text { Medium } \\
\text { fixed } \\
\text { bearing }\end{array}$ & $\begin{array}{l}\text { Conventional } \\
\text { polyethylene }\end{array}$ & $\begin{array}{l}\text { Increased anterior } \\
\text { posterior } \\
\text { translation }\end{array}$ & 9 to 15 & 30,31 \\
\hline Knee & $\begin{array}{l}\text { Medium } \\
\text { fixed } \\
\text { bearing }\end{array}$ & $\begin{array}{l}\text { Cross linked } \\
\text { polyethylene } \\
\text { (5 MRad) }\end{array}$ & $\begin{array}{l}\text { Increased anterior } \\
\text { posterior } \\
\text { translation }\end{array}$ & 4.5 to 8.5 & \\
\hline Knee & $\begin{array}{l}\text { Medium } \\
\text { fixed } \\
\text { bearing }\end{array}$ & $\begin{array}{l}\text { Conventional } \\
\text { polyethylene }\end{array}$ & Lift off & 12 to 19 & 32 \\
\hline
\end{tabular}

demands demonstrated the potential for wear debris induced osteolysis in the knee with conventional polyethylene. With cross linked polyethylene and high kinematic inputs of increased AP translation, the wear rate increased compared to the standard conditions, but remained below $10 \mathrm{~mm}^{3}$ per million cycles, demonstrating the potential advantage of cross linked polyethylene in high demand kinematic conditions.

Conditions associated with degradation of prostheses. In this section variations in the wear rate associated with degradation of the prostheses and in particular deterioration of the femoral head roughness were considered (Table 4), which is particularly relevant as the prosthesis enters the second decade of its life in vivo. Clinically, damage to smooth metallic femoral heads has been observed in retrievals ${ }^{\mathbf{1 0}}$ and this has been replicated in the simulator with discrete scratches on the femoral head which produced an increase in polyethylene wear.

Damage to the femoral head produced a three-fold increase in wear with conventional polyethylene, compared to standard condition testing, substantially increasing the risk of osteolysis. While hip simulator studies have not been undertaken on highly cross linked polyethylene on scratched femoral heads, pin on plate studies of highly cross linked polyethylene also show a three-fold increase in wear rate $^{39}$ on scratched counter-faces. If this was replicated with scratched heads in the simulator pre-clinically and in the patient, this would lead to wear rates in the range 15 to $30 \mathrm{~mm}^{3}$ per million cycles and potential for osteolysis.

\section{Discussion}

Patients, clinicians, regulators and healthcare providers expect greater than $90 \%$ success rate after ten years implantation for joint replacements. Wear and adverse reactions to wear debris remain the major cause of failure in joint replacements. ${ }^{1-3}$ Pre-clinical tribological simulation and evaluation, aligned to developments of

Table 4 Deterioration of femoral head roughness

\begin{tabular}{llllll}
\hline & & & & & \\
Prosthesis & Material & $\begin{array}{l}\text { Wear rate } \\
\left(\mathrm{mm}^{3} \text { per }\right. \\
\text { million } \\
\text { cycles })\end{array}$ & Reference \\
\hline Hip & $\begin{array}{l}\text { Conventional } \\
\text { polyethylene }\end{array}$ & 28 & $\begin{array}{l}\text { Scratched } \\
\text { head }\end{array}$ & 100 to 140 & 6 \\
\hline
\end{tabular}


improved prosthetic solutions, can contribute to improved wear performance, reliability, safety and efficacy and meeting the expectations of users and patients. However, current standard pre-clinical tests, which focus on a single set of conditions are not adequate to evaluate performance across a much wider set of conditions found clinically. Indeed current ISO standard pre-clinical tests have indicated the adequate wear performance for the majority of current prostheses and have not been able to predict wear related failure or wear mechanisms found clinically in some current devices. Many clinical failures from high wear currently occur under conditions outside the standard walking cycle condition described in the standard pre-clinical test.

A new stratified approach to pre-clinical evaluation has been defined and proposed, which provides a frame work to systematically assess the wider range of clinical conditions and variables found in the patient population in order to more rigorously evaluate the tribology of joint replacements. The key to the success of this approach is to define conditions that are realistic and representative of the clinical environment, which can differentiate current devices and which can be validated against current clinical experience. Equally important is the ability to assess the level and change in wear rate with respect to that obtained under standard walking conditions, under which the majority of current prostheses perform adequately, and to compare to wear rates of current materials to clinical performance.

In first part of this paper we have established the baseline tribological performance under the current standard walking cycle test for different bearing materials for historical and current prostheses from our existing data set of over 5 billion test cycles. When combined with clinical experience, we have defined indicative levels of acceptable performance in terms of wear rates for different materials. This indicates a clinical tolerance of a greater wear rate for polyethylene than for metal, due to their differing bio-reactivity and cellular response.

The new stratified approach to pre-clinical testing has been demonstrated in the second part of the paper, with examples of how the different types of clinical conditions influence the wear rate of different prostheses. The amount and rate of increase in wear rate, as well as absolute level of the wear rate compared to the indicative level of acceptable performance is important in determining the clinical significance of the increased wear. Different types of prostheses have been found to respond differently to the different clinical conditions.

In the hip, the intersection of the wear contact patch of the head with the edge of the cup, which results in distinctive stripe wear on the femoral head, was produced by both translational or rotational mal-position of the prosthetic components. ${ }^{26}$ The effect of component mal-positioning and edge loading in the hip can lead to a tenfold increase in wear rate for some metal on metal bearings for both types of malposition and some ceramic on ceramic bearings under translational mal-position only. However the absolute level of wear rate is much higher in metal on metal bearing and the debris more reactive, and therefore more damaging clinically.

This new approach to pre-clinical testing also has allowed us to differentiate between different designs of metal on metal prostheses and different types of ceramic materials, which were not differentiated by the standard test cycle.

In the polyethylene hip, cross linking has been demonstrated to reduce wear under standard conditions, but concerns remain around deterioration of the metallic femoral head with the potential of causing increased wear in the longer term. The scratch resistant ceramic femoral head may mitigate this risk..$^{40,41}$

In the knee an increase in polyethylene wear has been demonstrated with increased kinematic demand, through both an increase anterior posterior translation and femoral lift off. Moderately cross linked polyethylene can reduce the wear under these high demand conditions as well as under standard conditions. Given the wide variations in kinematics seen in knee replacement patients it is essential to study performance of current knee designs under a wider set of kinematic conditions, 
beyond the single set defined by the standard, rather than try to refine or define the single standard condition to match the ideal patient.

Conditions associated with every single movement or all activities are likely to have more clinical impact than conditions associated with specific activities which occur less frequently. For example a mal-positioned prosthesis will affect every step and result in elevation of wear on every step, as will offset deficiency and leg length discrepancy, which can also cause rim loading in the hip. Similarly in the knee joint laxity and instability, increased AP displacement, or femoral condylar lift off can cause high kinematic demand and increased wear on every step. In contrast raising from a chair, or stair climbing may only impact on less than ten percent of the tribological cycles. Additionally deterioration of prosthetic material or design over time will also impact on the wear on every single movement.

Clearly only a few examples of the application of specific conditions in the stratified framework for pre-clinical testing have been presented in this paper and to date we have not addressed the variation intrinsic in the populations receiving prostheses. Examples of immediate gaps in the knowledge base include, in the hip, the effect of component position on polyethylene wear, particularly the effect of edge loading in thinner polyethylene liners, the influence of cup version on edge contact and wear, the potential for degradation of both cross linked polyethylene and ceramic matrix composites and the role of variations in individual patient reactivity and their tolerance to debris of different types. In the knee surgical alignment and positioning as well as further studies of different kinematic inputs are required. These are just a few examples of different clinical conditions requiring further investigation.

From an academic perspective accurate prediction of wear rates is required. However from a clinical, patient and user perspective, it is more important to define the envelope of conditions in which different prostheses can operate effectively with acceptably low wear rates, and to identify combinations of prosthesis technology and clinical conditions where wear rates exceed the acceptable levels or start to increase rapidly, recognising that each material has a different safe acceptable level of wear rate. Additionally given that the prostheses operate in a complex set of clinical conditions it will be important in the future to address interactions between the different conditions within the groups of conditions and across the groups of conditions.

Bioengineers, tribologists and implant designers have successfully reduced the average wear rates in current prosthetic designs under standard conditions to acceptable low levels for each material type. It is now necessary to focus on producing acceptable tribological performance in the much wider set of conditions found clinically. The stratified approach presented in this paper provides a frame work in which to address this future challenge.

\section{Acknowledgements}

JF is an NIHR senior investigator. His research is funded by the EPSRC, by the NIHR LMBRU Leeds Musculoskeletal Biomedical Research Unit, by the centre of excellence in Medical Engineering funded by Wellcome Trust and EPSRC WT 088908/z/09/z, by the Innovation and Knowledge Centre in medical technologies, regenerative therapies and devices, funded by EPSRC, BBSRC and TSB and by ORUK, ARUK, NIH and EU-ERC.

\section{References}

1 J. Fisher, Tribology of artificial joints, Proc. Inst. Mech. Eng., Part H, 1991, 205, 73-79.

2 E. Ingham and J. Fisher, Biological reactions to wear debris in total joint replacement, Proc. Inst. Mech. Eng., Part H, 2000, 214, 21-37.

3 E. Ingham and J. Fisher, The role of macrophages in osteolysis of total joint replacement, Biomaterials, 2005, 26, 1271-1286. 
4 R. J. A. Bigsby, C. S. Hardaker and J. Fisher, Wear of ultra-high molecular weight polyethylene acetabular cups in a physiological hip joint simulator in the anatomical position using bovine serum as a lubricant, Proc. Inst. Mech. Eng., Part H, 1997, 211, 265-269.

5 P. S. M. Barbour, M. H. Stone and J. Fisher, A hip joint simulator study using simplified loading and motion cycles generating physiological wear paths and rates, Proc. Inst. Mech. Eng., Part H, 1999, 212, 455-467.

6 P. S. M. Barbour, M. H. Stone and J. Fisher, A hip joint simulator study using new and physiologically scratched femoral heads with ultra-high molecular weight polyethylene acetabular cups, Proc. Inst. Mech. Eng., Part H, 2000, 214, 569-576.

7 J. Fisher, H. M. J. McEwen, P. I. Barnett, C. J. Bell, T. D. Stewart, M. H. Stone and E. Ingham, Total knee replacement - practical considerations (i) Wear of polyethylene in artificial knee joints, Curr. Orthop., 2001, 15, 399-405.

8 P. I. Barnett, H. M. J. McEwen, D. D. Auger, M. H. Stone, E. Ingham and J. Fisher, Investigation of wear of knee prostheses in a new displacement/force-controlled simulator, Proc. Inst. Mech. Eng., Part H, 2002, 216, 51-61.

9 H. M. J. McEwen, J. Fisher, A. A. J. Goldsmith, D. D. Auger, C. Hardaker and M. H. Stone, Wear of fixed bearing and rotating platform mobile bearing knees subjected to high levels of internal and external tibial rotation, J. Mater. Sci.: Mater. Med., 2001, 12, 1049-1052.

10 J. L. Tipper, E. Ingham, J. L. Hailey, A. A. Besong, J. Fisher, B. M. Wroblewski and M. H. Stone, Quantitative analysis of polyethylene wear debris, wear rate and head damage in retrieved Charnley hip prostheses. Materials Science, J. Mater. Sci.: Mater. Med., 2000, 11, 117-124.

11 E. Ingham, J. Fisher and M. H. Stone, Wear of historical polyethylene in hip prostheses. Biomechanical success and a biological failure, Hip Int., 2003, 13, S17-S27.

12 A. L. Galvin, J. L. Tipper, L. M. Jennings, M. H. Stone, Z. M. Jin, E. Ingham and J. Fisher, Wear and biological activity of highly crosslinked polyethylene in the hip under low serum protein concentrations, Proc. Inst. Mech. Eng., Part H, 2007, 221, 1-10.

13 J. E. Nevelos, E. Ingham, C. Doyle, A. B. Nevelos and J. Fisher, The influence of acetabular cup angle on the wear of "BIOLOX Forte" alumina ceramic bearing couples in a hip joint simulator, J. Mater. Sci.: Mater. Med., 2001, 12, 141-144.

14 P. J. Firkins, J. L. Tipper, M. R. Saadatzadeh, E. Ingham, M. H. Stone, R. Farrar and J. Fisher, Quantitative analysis of wear and wear debris from metal-on-metal hip prostheses tested in a physiological hip joint simulator, Bio-Med. Mater. Eng., 2001, 11, 143-157.

15 J. Nevelos, E. Ingham, C. Doyle, R. Streicher, A. Nevelos, W. Walter and J. Fisher, Microseparation of the centers of alumina-alumna artificial hip joints during simulator testing produces clinically relevant wear and patterns, J. Arthroplasty, 2000, 15, 793-795.

16 J. E. Nevelos, E. Ingham, C. Doyle, A. B. Nevelos and J. Fisher, Analysis of retrieved alumina ceramic components for Mittelmeier total hip prostheses, Biomaterials, 1999, 20, $1833-1840$.

17 J. E. Nevelos, Prudhommeaux, M. Hamadouche, C. Doyle, E. Ingham, A. Meunier, A. B. Nevelos, L. Sedel and J. Fisher, Comparative analysis of two different types of alumina-alumina hip prosthesis retrieved for aseptic loosening, J. Bone Jt. Surg., Br. Vol., 2001, 83, 598-603.

18 T. Stewart, J. L. Tipper, R. Streicher, E. Ingham and J. Fisher, Long-term wear or HIPed alumina on alumina bearings for THR under microseparation conditions. Journal of Materials Science, J. Mater. Sci.: Mater. Med., 2001, 12, 1053-1056.

19 A. Hatton, J. E. Nevelos, A. A. Nevelos, R. E. Banks, J. Fisher and E. Ingham, Aluminaalumina artificial hip joints. Part I: A histological analysis and characterisation of wear debris by laser capture micro-dissection of tissues retrieved at revision, Biomaterials, 2002, 23, 3429-3440.

20 S. Williams, M. Butterfield, T. Stewart, E. Ingham, M. H. Stone and J. Fisher, Wear and deformation of ceramic-on-polyethylene total hip replacements with joint laxity and swing phase microseparation, Proc. Inst. Mech. Eng., Part H, 2003, 217, 147-153.

21 S. Williams, T. D. Stewart, E. Ingham, M. H. Stone and J. Fisher, Metal-on-Metal bearing wear with different swing phase loads, J. Biomed. Mater. Res., 2004, 70B(2), 233-239.

22 J. Fisher, Z. Jin, J. Tipper, M. Stone and E. Ingham, Tribology of Alternative Bearings, Clin. Orthop. Relat. Res., 2006, 453, 25-34.

23 S. Williams, I. Leslie, G. Isaac, Z. Jin, E. Ingham and J. Fisher, Tribology and wear of metal-on-metal hip prostheses: influence of cup angle and head position, J. Bone Jt. Surg., 2008, 90(Supplement 3), 111-117.

24 I. J. Leslie, S. Williams, G. Isaac, E. Ingham and J. Fisher, High Cup Angle and Microseparation Increase the Wear of Hip Surface Replacements, Clin. Orthop. Relat. Res., 2009, 467, 2259-2265. 
25 M. Al-Hajjar, I. J. Leslie, J. Tipper, S. Williams, J. Fisher and L. M. Jennings, Effect of cup inclination angle during microseparation and rim loading on the wear of BIOLOX ${ }^{\circledR}$ delta ceramic-on-ceramic total hip replacement, J. Biomed. Mater. Res. B, 2010, 95, $263-268$.

$26 \mathrm{~J}$. Fisher, Bioengineering reasons for failure of metal on metal hip prostheses, a bioengineers perspective, J. Bone Jt. Surg., Br. Vol., 2011, 93, 1001-1004.

27 P. J. Firkins, J. L. Tipper, E. Ingham, M. H. Stone, R. Farrar and J. Fisher, Influence of simulator kinematics on the wear of metal-on-metal hip prostheses, Proc. Inst. Mech. Eng., Part H, 2001, 215, 119-121.

28 C. Brockett, S. Williams, Z. M. Jin, G. Isaac and J. Fisher, Friction of total hip replacements with different bearings and loading conditions, J. Biomed. Mater. Res. B, 2007, 81(13), 508-515.

29 S. Williams, D. Jalai-Vahid, C. L. Brockett, Z. Jin, M. H. Stone, E. Ingham and J. Fisher, Effect of swing phase load on metal-on-metal hip lubrication, friction and wear, $J$. Biomech., 2006, 39, 2274-2281.

30 H. M. J. McEwen, P. I. Barnett, C. J. Bell, R. Farrar, D. D. Auger, M. H. Stone and $\mathrm{J}$. Fisher, The influence of design, materials and kinematics on the in vitro wear of total knee replacements, J. Biomech., 2005, 38, 357-365.

31 J. Fisher, L. M. Jennings, A. L. Galvin, Z. M. Jin, M. H. Stone and E. Ingham, 2009 Knee Society Presidential Guest Lecture: Polyethylene Wear in Total Knees, Clin. Orthop. Relat. Res., 2010, 468, 12-18.

32 L. M. Jennings, C. J. Bell, E. Ingham, R. D. Komistek, M. H. Stone and J. Fisher, The influence of femoral condylar lift-off on the wear of artificial knee joints. Journal of Engineering in Medicine, Proc. Inst. Mech. Eng., Part H, 2007, 221(3), 305-314.

33 J. Bell, J. L. Tipper, E. Ingham, M. H. Stone and J. Fisher, The influence of phospholipid concentration in protein-containing lubricants on the wear of ultra-high molecular weight polyethylene in artificial hip joints, Proc. Inst. Mech. Eng., Part H, 2001, 215, 259-263.

34 J. B. Matthews, A. A. Besong, T. R. Green, M. H. Stone, B. M. Wroblewski, J. Fisher and E. Ingham, Evaluation of the response of primary human peripheral blood mononuclear phagocyted to challenge with in vitro generated clinically relevant UHMWPE particles of known size and dose, J. Biomed. Mater. Res., 2000, 52, 296-307.

35 A. A. Besong, J. L. Tipper, E. Ingham, M. H. Stone, B. M. Wroblewski and J. Fisher, Quantitative comparison of wear debris from UHMWPE that has and has not been sterilised by gamma irradiation, J. Bone Jt. Surg., Br. Vol., 1998, 80, 340-344.

36 S. Williams, A. Schepers, G. Isaac, C. Hardaker, E. Ingham, D. van der Jagt, A. Breckon and J. Fisher, THE 2007 OTTO AUFRANC AWARD: Ceramic-on-Metal Hip Arthroplasties A Comparative In Vitro and In Vivo Study, Clin. Orthop. Relat. Res., 2007, 465, 23-32.

37 I. Leslie, S. Williams, C. Brown, G. Isaac, Z. Jin, E. Ingham and J. Fisher, Effect of bearing size on the long-term wear, wear debris, and ion levels of large diameter metal-on-metal hip replacements-An in vitro study, J. Biomed. Mater. Res., Part B, 2008, 87B, 163-172.

38 I Leslie, Surface engineered hip prostheses, PhD thesis, University of Leeds, 2008.

39 A. L. Galvin, L. Kang, J. L. Tipper, M. H. Stone, E. Ingham, Z. Jin and J. Fisher, Wear of crosslinked polyethylene under different tribological conditions, J. Mater. Sci.: Mater. Med., 2006, 17(3), 235-243.

40 H. Minakawa, M. H. Stone, B. M. Wroblewski, J. G. Lancaster, E. Ingham and J. Fisher, Quantification of third-body damage and its effect on UHMWPE wear with different types of femoral head, J. Bone Jt. Surg., Br. Vol., 1998, 80, 894-9.

41 A. L. Galvin, L. M. Jennings, J. L. Tipper, E. Ingham and J. Fisher, Wear and creep of highly cross linked polyethylene against cobalt chrome and ceramic femoral heads, Proc. Inst. Mech. Eng., Part H, 2010, 224, 1175-1183. 